\title{
Prior elicitation of the efficacy and tolerability of
}

\section{Methotrexate and Mycophenolate Mofetil in Juvenile}

\section{Localised Scleroderma [version 1; peer review: 2 approved]}

\author{
Yasin Desai ${ }^{1}$, Thomas Jaki ${ }^{1,2}$, Michael W Beresford ${ }^{3,4}$, Thomas Burnett ${ }^{1}$, \\ Despina Eleftheriou ${ }^{5,6}$, Heidi Jacobe7, Valentina Leone ${ }^{8}$, Suzanne Li9, \\ Pavel Mozgunov ${ }^{1}$, Athimalaipet V Ramanan ${ }^{10}$, Kathryn S Torok ${ }^{11}$, \\ Marina E Anderson 12,13, Jordi Anton 14, Tadej Avcin'15, Jessie Felton (iD16, \\ Ivan Foeldvari17, Bisola Laguda ${ }^{18}$, Flora McErlane ${ }^{19}$, Lindsay Shaw ${ }^{6,10}$, \\ Francesco Zulian (D)20, Clare E Pain (D)3
}

\footnotetext{
${ }^{1}$ MPS Research Unit, Department of Mathematics and Statistics, Lancaster University, Lancaster, LA1 4YF, UK

${ }^{2}$ MRC Biostatistics Unit, University of Cambridge, Cambridge, CB2 OSR, UK

${ }^{3}$ Department of Paediatric Rheumatology, Alder Hey Children's NHS Foundation Trust, Liverpool, L12 2AP, UK

4Institute of Life Course and Medical Sciences, University of Liverpool, Liverpool, L69 3BX, UK

5 University College London, Institute of Child Health, London, WC1N 1EH, UK

${ }^{6}$ Department of Paediatric Rheumatology, Great Ormond St Hospital NHS Foundation Trust, London, WC1N 3JH, UK

7UT Southwestern Medical Center, Dallas, Texas, TX 75390, USA

8Paediatric Rheumatology Department, Leeds Children Hospital (Leeds Teaching Hospitals) and University of Leeds, Leeds, LS1 3EX, UK

${ }^{9}$ Department of Pediatrics, Joseph M. Sanzari Children's Hospital, Hackensack University Medical Center \& Hackensack Meridian School of Medicine, Hackensack, New Jersey, NJ 07601, USA

10University Hospitals Bristol NHS Foundation Trust \& Translational Health Sciences, Bristol, BS1 3NU, UK

${ }^{11}$ Division of Rheumatology, Department of Pediatrics, Children's Hospital of Pittsburgh, University of Pittsburgh, Pittsburgh, PA 15260, USA

12Department of Rheumatology, Liverpool University Hospitals NHS Foundation Trust, Liverpool, L9 7AL, UK

${ }^{13}$ Lancaster Medical School, Lancaster University, Lancaster, LA1 4YF, UK

${ }^{14}$ Pediatric Rheumatology, Hospital Sant Joan de Déu, University of Barcelona, Barcelona, Barcelona, 08007, UK

${ }^{15}$ Department of Allergology, Rheumatology and Clinical Immunology, University Children's Hospital, University Medical Centre, Ljubljana, 1000 Ljubljana, Slovenia

${ }^{16}$ Department of Dermatology, Brighton and Sussex University Hospitals \& Royal Alexandra Children's Hospital, Brighton, BN2 1DH, UK

${ }^{17}$ Hamburg Centre for Pediatric and Adolescence Rheumatology, Hamburg, 22081 Hamburg, Germany

${ }^{18}$ Department of Paediatric Dermatology, Chelsea and Westminster Hospital, London, SW10 9NH, UK

${ }^{19}$ Department of Paediatric Rheumatology, Great North Children's Hospital, Newcastle, NE1 4LP, UK

${ }^{20}$ Department of Woman's and Child's Health, University of Padova, Padua, 35122 Padua, Italy
}

V1 First published: 09 Sep 2021, 3:20

https://doi.org/10.12688/amrcopenres.13008.1

Latest published: 09 Sep 2021, 3:20

https://doi.org/10.12688/amrcopenres.13008.1

\section{Open Peer Review}

Approval Status

\section{Abstract}

Background Evidence is lacking for safe and effective treatments for juvenile localised scleroderma (JLS). Methotrexate (MTX) is commonly 
used first line and mycophenolate mofetil (MMF) second line, despite a limited evidence base. A head to head trial of these two medications would provide data on relative efficacy and tolerability. However, a frequentist approach is difficult to deliver in JLS, because of the numbers needed to sufficiently power a trial. A Bayesian approach could be considered.

Methods An international consensus meeting was convened including an elicitation exercise where opinion was sought on the relative efficacy and tolerability of MTX compared to MMF to produce prior distributions for a future Bayesian trial. Secondary aims were to achieve consensus agreement on critical aspects of a future trial. Results An international group of 12 clinical experts participated. Opinion suggested superior efficacy and tolerability of MMF compared to MTX; where most likely value of efficacy of MMF was 0.70 (95\% confidence interval (CI) $0.34-0.90$ ) and of MTX was 0.68 (95\% CI $0.41-0.8)$. The most likely value of tolerability of MMF was $0.77(95 \% \mathrm{CI}$ $0.3-0.94$ ) and of MTX was 0.62 (95\% CI 0.32-0.84). The wider CI for MMF highlights that experts were less sure about relative efficacy and tolerability of MMF compared to MTX. Despite using a Bayesian approach, power calculations still produced a total sample size of 240 participants, reflecting the uncertainty amongst experts about the performance of MMF.

Conclusions Key factors have been defined regarding the design of a future Bayesian approach clinical trial including elicitation of prior opinion of the efficacy and tolerability of MTX and MMF in JLS. Combining further efficacy data on MTX and MMF with prior opinion could potentially reduce the pre-trial uncertainty so that, when combined with smaller trial sample sizes a compelling evidence base is available.

\section{Keywords}

juvenile localised scleroderma, methotrexate, mycophenolate mofetil, Bayesian approach, prior elicitation

version 1
Magreb, Croatia 2021
Medicine, Zagreb, Zagreb, Croatia
2. Sandy Hong ID, University of Iowa Stead
Family Children's Hospital, Iowa City, USA
Any reports and responses or comments on the
article can be found at the end of the article.


Corresponding author: Clare E Pain (clare.pain@alderhey.nhs.uk)

Author roles: Desai Y: Data Curation, Formal Analysis, Investigation, Methodology, Project Administration, Resources, Software, Visualization, Writing - Original Draft Preparation, Writing - Review \& Editing; Jaki T: Conceptualization, Data Curation, Formal Analysis, Funding Acquisition, Investigation, Methodology, Project Administration, Resources, Supervision, Visualization, Writing - Original Draft Preparation; Beresford MW: Conceptualization, Funding Acquisition, Writing - Original Draft Preparation; Burnett T: Data Curation, Formal Analysis, Software, Writing - Review \& Editing; Eleftheriou D: Conceptualization, Funding Acquisition, Methodology, Writing Review \& Editing; Jacobe H: Data Curation, Writing - Review \& Editing; Leone V: Investigation, Writing - Review \& Editing; Li S: Data Curation, Investigation, Methodology, Writing - Review \& Editing; Mozgunov P: Data Curation, Formal Analysis, Software, Writing Review \& Editing; Ramanan AV: Conceptualization, Funding Acquisition, Writing - Review \& Editing; Torok KS: Data Curation, Investigation, Methodology, Writing - Review \& Editing; Anderson ME: Investigation, Writing - Review \& Editing; Anton J: Investigation, Writing - Review \& Editing; Avcin T: Investigation, Writing - Review \& Editing; Felton J: Investigation, Writing - Review \& Editing; Foeldvari I: Investigation, Writing - Review \& Editing; Laguda B: Investigation, Writing - Review \& Editing; McErlane F: Investigation, Writing - Review \& Editing; Shaw L: Investigation, Writing - Review \& Editing; Zulian F: Investigation, Writing - Review \& Editing; Pain CE : Conceptualization, Data Curation, Funding Acquisition, Methodology, Project Administration, Resources, Supervision, Visualization, Writing - Original Draft Preparation, Writing - Review \& Editing

Competing interests: DE Research grants and consultancy fees from SOBI, Lilly, Pfizer; JA grants and consultancy fees from Novartis, Roche, Gebro Rest of authors no disclosures

Grant information: The author(s) declared that no grants were involved in supporting this work.

Copyright: @ 2021 Desai $Y$ et al. This is an open access article distributed under the terms of the Creative Commons Attribution License, which permits unrestricted use, distribution, and reproduction in any medium, provided the original work is properly cited.

How to cite this article: Desai Y, Jaki T, Beresford MW et al. Prior elicitation of the efficacy and tolerability of Methotrexate and Mycophenolate Mofetil in Juvenile Localised Scleroderma [version 1; peer review: 2 approved] AMRC Open Research 2021 , 3:20 https://doi.org/10.12688/amrcopenres.13008.1

First published: 09 Sep 2021, 3:20 https://doi.org/10.12688/amrcopenres.13008.1 


\section{List of abbreviations}

CARRA, Childhood Arthritis \& Rheumatology Research Alliance;

CI, confidence intervals;

CS, corticosteroids;

DMARD, Disease Modifying Anti-Rheumatic Drug;

$\mathrm{IQR}$, interquartile range;

JLS, juvenile localised scleroderma;

LoSCAT, localized scleroderma cutaneous assessment tool;

LoSQI, Localised Scleroderma Quality of Life Instrument;

LS, localised scleroderma;

MAC, Morphea in Adults and Children cohort;

mLoSSI; modified localised scleroderma skin severity index;

MMF, mycophenolate mofetil;

MTX, methotrexate;

NRCOS, National Registry of Childhood Onset Scleroderma;

$\mathrm{p}_{\mathrm{MTX}}$, probability of successful treatment with methotrexate;

$\mathrm{p}_{\mathrm{MMF}}$, probability of successful treatment with mycophenolate mofetil;

$\mathrm{RCT}$, randomised controlled trial;

RPCT, randomised placebo controlled trial;

RIO, rational impartial observer;

$\mathrm{t}_{\mathrm{MTX}}$ probability of tolerating methotrexate;

$\mathrm{t}_{\mathrm{MMF}}$ probability of tolerating mycophenolate mofetil;

UK, United Kingdom

\section{Background}

Juvenile localised scleroderma (JLS) is characterised by chronic inflammation of the skin and adjacent tissue leading to fibrosis ${ }^{1}$. It is associated with significant complications that impact quality of life $^{2}$. The incidence rate of JLS in the UK is 3.4 per one million children per year and has a prevalence from 3.2 to 3.6 per 10000 children $^{3,4}$.

Treatment of JLS remains challenging. To date there has only been one randomised trial in JLS which was a randomised placebo-controlled trial (RPCT) of $\mathrm{MTX}^{5}$. At one year, a disease relapse rate of $32.6 \%$ was shown in the MTX group compared to $70.8 \%$ of the placebo group $(\mathrm{p}<0.005)$. This highlighted that MTX therapy is superior to placebo but may not be effective in controlling disease in one third of patients. In addition, significant side effects are associated with MTX $^{5-7}$ including gastro-intestinal symptoms, such as nausea, vomiting (20\% in the MTX arm of the RPCT) and anticipatory vomiting $(20 \% \text { in a North American prospective JLS cohort })^{8}$.
A UK wide study showed that children discontinuing MTX for JLS, reported medication side-effects as the primary reason?

An emerging alternative to MTX is $\mathrm{MMF}^{10,11}$. Clinical practice internationally confirms the common use of MMF in those that have failed MTX, despite a limited evidence base ${ }^{12,13}$. MMF reduces $\mathrm{B}$ and $\mathrm{T}$ lymphocyte proliferation ${ }^{14}$, attenuates fibrosis in vitro ${ }^{15}$, and in vivo by mitigating the inflammatory gene expression and skin score in scleroderma ${ }^{16}$. Therefore, it may have an effect on both the inflammatory and fibrotic aspects of this disease. A growing body of data from high-quality clinical trials in adults suggests that MMF is a well-tolerated alternative for the induction of remission of different autoimmune diseases ${ }^{17-20}$. The use of MMF in JLS may significantly reduce the burden of disease and drug toxicity.

Several evidence-based guidelines on the management of JLS have been published ${ }^{21-27}$. All include MTX as first line treatment together with corticosteroids (CS) and most suggest second line treatment with MMF. Multiple regimes for CS have been described, including both oral and intravenous s,8,13,28-31 $^{\text {. Consen- }}$ sus treatment plans formulated by the Childhood Arthritis and Rheumatology Research Alliance (CARRA) define three CS arms and the use of MTX first line with MMF as second line or add on therapy ${ }^{26}$.

Given the confirmed efficacy of MTX but with poor associated tolerability, and limited evidence base for MMF, a head to head study of MTX against MMF is warranted to allow direct comparison of the efficacy and tolerability of the two treatments. This would provide data to inform the usefulness (or otherwise) of MMF but also may demonstrate that MMF is potentially preferable as first line treatment. Unfortunately, a frequentist trial that compares these two agents would require large numbers of patients which is not feasible, even with international collaboration, in a rare disease like JLS. A frequentist trial design would require a total sample size of 320 patients, assuming a non-inferiority margin of $15 \%$, and (for example) a one-sided type-I error of 5\% and $90 \%$ power, if both treatments have a $70 \%$ response rate. With the number of new cases in the UK per year being estimated at 43 , it would take at least 15 years to complete the study, presuming a $50 \%$ consent rate in all centres ${ }^{3}$. An alternative to the conventional frequentist statistical methodology is the Bayesian framework for the design and analysis of a clinical trial $^{32}$. Bayesian methodology utilises data from a randomised controlled trial (RCT) alongside prior opinion from an expert group of the efficacy and tolerability of each drug. This prior opinion can be informed from multiple sources including clinical experience of the experts in using the two medicines, and evidence from published and unpublished datasets. As MMF is commonly used second line, a clinical trial using a Bayesian approach is appealing because experts will have clinical experience of using both drugs and observational data sources exist to inform prior opinion.

By utilising the prior information in conjunction with the trial data, the required sample size can be reduced provided that 
the prior information agrees with the trial data whilst still achieving desirable operating characteristics. If, however, the prior information is in conflict with information from the subsequent trial, conclusions may be less precise. Therefore, this methodology cannot, and should not, be used ad hoc to lower required sample size.

In this work we describe the underlying trials methodology and report the results of an international consensus meeting to establish the pre-trial evidence base of the two treatments. Here, we utilised expert opinion to elicit prior opinion, an approach that has been previously used in paediatric rheumatology clinical trials such as the MYPAN trial ${ }^{33,34}$. On the basis of these results we developed the design of a potential future trial comparing MMF to MTX.

\section{Methods}

Synthesis of data from published and unpublished sources to define primary outcome and inform prior elicitation

A study group of experts (CP, DE, SL, HJ, KT, VL, YD, TJ) met frequently via teleconference to discuss relevant data from pre-existing databases to define what constitutes successful treatment and tolerance. A scoping exercise for available tools for measuring tolerability was performed. A literature review of efficacy and tolerability of MTX and MMF was undertaken by systematic review researchers at Keele University, UK (Jo Jordan, Nadia Corp).

\section{Establishing a group of experts to determine consensus} prior opinion

An electronic survey was sent to potentially eligible clinician's through a number of national/international societies and professional organisations. Direct invitations were sent to 9 individuals who had published sentinel research on JLS. All participants of the prior elicitation meeting were clinicians, chosen on the basis of pre-defined definitions of a clinical expert, ensuring representation from UK and non-UK sites within the constraints of the funding of the study. Definition of clinical expert, identification of eligible clinicians, response to the survey and methodology for selection of experts can be found in extended data in the Data Availability section.

Establishing consensus on key elements of a future RCT and prior opinion of efficacy \& tolerability of MTX and MMF

Figure 1 outlines the agenda of the prior elicitation day. Participants were sent preparatory material before the meeting summarising key elements of a future proposed trial in JLS and current available evidence for efficacy and tolerability of the two medicines. Before any elicitations could take place, a recap of current evidence of efficacy and tolerability of MTX and MMF was presented together with evidence of CS regimes. Consensus agreement was sought on certain key elements of a clinical trial including primary outcome definition and CS regimes.

The consensus meeting was conducted under the premise that the future trial will be a multi-centre randomised controlled open label study of MMF and CS compared to MTX and CS in children and young adults with active JLS using a Bayesian design. It was stipulated that randomisation would be $1: 1$ between MTX $15 \mathrm{mg} / \mathrm{m} 2$ by oral or subcutaneous route once weekly ( $\max 25 \mathrm{mg}$ weekly) together with a CS induction regime (to be confirmed) and MMF $600 \mathrm{mg} / \mathrm{m} 2$ orally twice daily (maximum $2 \mathrm{~g}$ daily) and $\mathrm{CS}$ induction regime

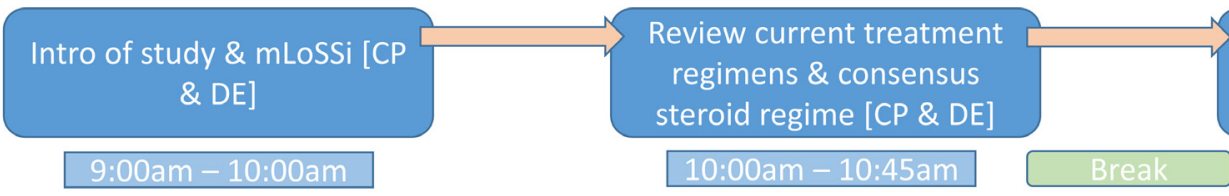

Presentation of Bayesian methodology [YD \&T]]

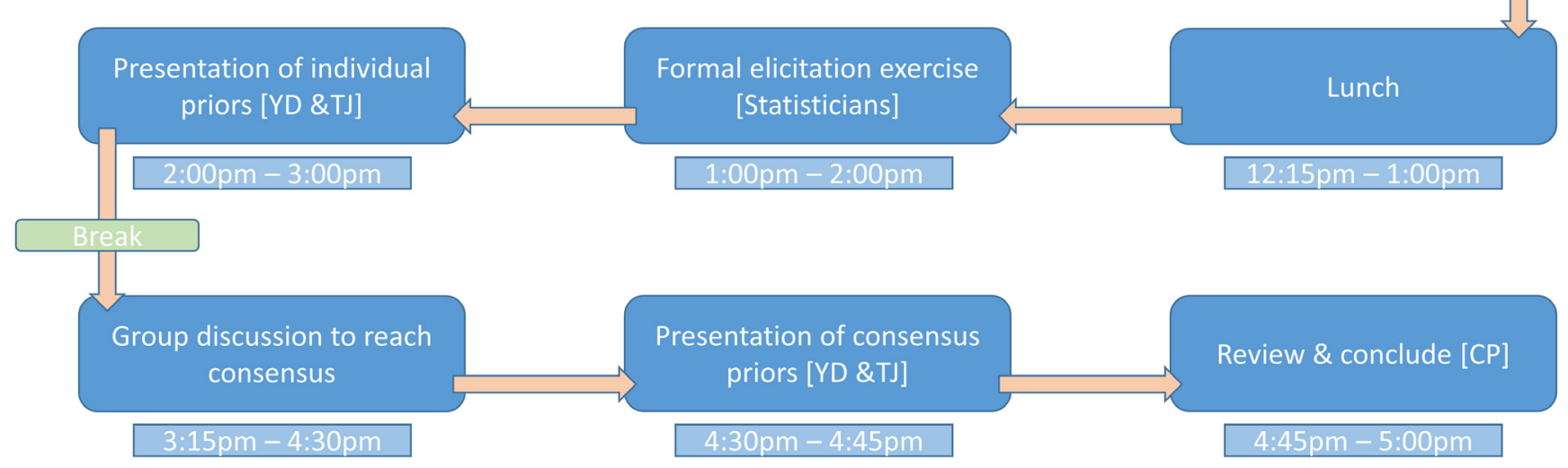

Figure 1. Outline of events for the prior elicitation meeting. 
(to be confirmed). Predefined inclusion criteria were set before the elicitation exercise (extended data in the Data Availability section).

An introduction to Bayesian methodology followed by an elicitation exercise to formulate prior distributions occurred. Specifically, we were interested in: $\mathrm{p}_{\mathrm{MTX}}$ (probability of successful treatment with MTX), $\mathrm{p}_{\mathrm{MMF}}$ (probability of successful treatment with MMF), $\mathrm{t}_{\mathrm{MTX}}$ (probability of tolerating MTX) and $\mathrm{t}_{\mathrm{MMF}}$ (probability of tolerating MMF).

Experts underwent training in understanding statistical terminology and methods, including probability density functions and Bayesian methodology.

The questions used to elicit and characterise expert's opinion were based on those used in the MYPAN trial ${ }^{32,33}$. These were adjusted to suit this scenario, following the definitions of successful treatment and tolerance defined above (questionnaire provided in extended data in the Data Availability section).

Each expert was asked to provide initial responses. In a oneto-one meeting with a statistician the $\mathrm{R}$ Shiny application was used to produce graphical results of the prior distributions using these initial responses to see if the characterisation was according to their expectation ${ }^{35,36}$. Alterations were made as required until the resulting distributions adequately reflected the individual's opinion.

Once all the individual prior distributions were obtained, they were presented to all experts collectively. Behavioural aggregation method was used to arrive at consensus through a discussion-based method. Any distributions that significantly differed to the rest were highlighted to further probe the group to come to a decision.

A rational impartial observer (RIO) was used from the Sheffield Elicitation Framework, to eliminate the idea of the consensus distribution becoming one expert's opinion ${ }^{37}$.

\section{Statistical approach for establishing Bayesian prior distributions}

The R Shiny package was used to create the application, modifying the application used in the MYPAN study $32,33,35,36$.

Prior distributions were elicited on the efficacy and tolerability of MTX, which was viewed as the control treatment. The endpoints for efficacy/tolerability were modelled as binary (i.e. success for treatment - Yes/No and tolerated treatment - Yes/No) and the log odds ratio was used to compare the two treatments for efficacy, $\theta_{\text {efficacy, }}$ and tolerability, $\theta_{\text {tol }}$. We define $\theta_{\text {efficacy }}$ and $\theta_{\text {tol }}$ as

$$
\theta_{\text {efficacy }}=\log \left(\frac{\mathrm{p}_{\mathrm{MMF}}\left(1-\mathrm{p}_{\mathrm{MTX}}\right)}{\mathrm{p}_{\mathrm{MTX}}\left(1-\mathrm{p}_{\mathrm{MMF}}\right)}\right) \quad \theta_{\text {tol }}=\log \left(\frac{\mathrm{t}_{\mathrm{MMF}}\left(1-\mathrm{t}_{\mathrm{MTX}}\right)}{\mathrm{t}_{\mathrm{MTX}}\left(1-\mathrm{t}_{\mathrm{MMF}}\right)}\right)
$$

such that positive values indicate MMF is superior to MTX and negative values correspond to better outcomes on MTX over MMF.
The parameters $\mathrm{p}_{\mathrm{MTX}}, \mathrm{t}_{\mathrm{MTX}}, \theta_{\text {efficacy }}, \theta_{\text {tol }}$ were elicited directly whilst the prior distributions of $\mathrm{p}_{\mathrm{MMF}}$ and $\mathrm{t}_{\mathrm{MMF}}$, were calculated analytically through a numerical integration algorithm. This allowed the pair of parameters $\left(\mathrm{p}_{\mathrm{MTX}}, \theta_{\text {efficacy }}\right)$ to be treated as independent of each other ${ }^{32,33}$.

$\mathrm{p}_{\mathrm{MTX}}$ and $\mathrm{t}_{\mathrm{MTX}}$ were modelled as beta distributions while Gaussian prior distributions were used to model $\theta_{\text {efficacy }}$ and $\theta_{\text {tol }}$.

\section{Ethical approval}

Ethical approval was not required as participants volunteered to take part as experts and no patients were involved.

\section{Results}

Establishment of primary outcome measure and consensus agreement on key elements of trial design

The Localised Scleroderma Cutaneous Assessment Tool (LoSCAT) is a validated measure in JLS which combines activity (mLoSSI) and damage (LoSDI) components ${ }^{38,39}$. It is an easy to use skin score which can be completed by clinicians in the clinic room without specialist equipment. Reliability has been tested in several cohorts including adults and as an outcome measure in clinical trials ${ }^{8,40-44}$. The mLoSSI activity component was chosen as the measure of efficacy for the consensus meeting. However, a study comparing efficacy alone may not address patient need. Patients and families in the UK expressed the need for more tolerable treatments, specifically related to intolerance from MTX (unpublished data from Scleroderma \& Raynaud's UK family day). We therefore agreed a composite primary outcome measure of efficacy and tolerability could be advantageous, hypothesising that whilst efficacy may be similar, tolerability may be better with MMF.

Choice of this composite primary outcome was made after review of pre-existing databases. These databases included: the National Registry of Childhood Onset Scleroderma (NRCOS) $)^{8,41,45,46}$, the Morphea in Adults and Children (MAC) cohort $^{47-49}$, and JLS pilot Consensus Treatment Plan studies ${ }^{50}$, which combined has longitudinal standardly collected prospective outcome data on over 900 localised scleroderma (LS) subjects (497 JLS, rest adults with LS) ${ }^{51}$. Average baseline mLoSSI (in all subtypes and specifically in head involvement), expected change in mLoSSI with treatment, minimal mLoSSI for entry into an RCT, time frame for primary outcome measure change and side-effects of MTX and MMF within these cohorts were reviewed.

Efficacy was agreed to be measured by the mLoSSI score, where inactive disease was defined as mLoSSI score of 0 and active disease as mLoSSI of 1 or greater. No ideal tool could be identified to measure tolerability of MTX and MMF. Therefore, a pragmatic definition of intolerance was agreed as the "need to permanently stop or reduce dose of a drug because of adverse events (patient reported or laboratory abnormalities) or the need to add in additional medications to counteract side-effects (e.g. anti-emetic)'. In both cases of efficacy and tolerability, a binary measure occurs with a positive result represented by a 1 and a negative result by 0 . 
In June 2019, twelve international clinicians with expertise in JLS including 3 dermatologists attended the face-to-face consensus meeting (extended data Appendix S1). Several key statements required consensus agreement prior to the elicitation process. These are summarised in Table 1.

Three CS regimens (A, B, C) were outlined based on a literature review of current evidence. A further regimen (D) was agreed on at the meeting which represented a regimen currently used in practice by several of the experts. After an initial discussion of the merits and demerits of the different regimens, consensus was sought through a process of elimination and voting about the different options. The four regimens that were discussed are given in Table 2 as well as the number of votes to help arrive at consensus. All experts agreed that regimen B was the most acceptable within a clinical trial setting.

\section{Individual prior distributions}

Figure 2 summarises four plots showing the individual prior distributions about the efficacy and tolerability of MTX and

\section{Table 1. Key statements and consensus agreements.}

\section{Statement}

Primary endpoint* would be measured at 12 months

Inactive disease is defined as mLoSSI score of 0

Because of the paucity of evidence in JLS, the route of administration of MTX (oral versus subcutaneous) would not influence the experts prior opinion on efficacy and tolerability of MTX

Inclusion criteria for the proposed clinical trial should include all subtypes of JLS where a DMARD is deemed necessary by the clinician, specifically isolated linear head lesions can also be included

Exclusion criteria would include participants where the main indication for starting a DMARD was due to extra-cutaneous manifestations such as uveitis or arthritis as the primary efficacy outcome (mLoSSI) only measures skin involvement

*Primary endpoint binary composite measure of efficacy (as measured by a mLoSSI score of 0 ) and tolerability (as measured by the absence of the need to permanently stop or reduce dose of a drug because of adverse events (patient reported or laboratory abnormalities) or the need to add in additional medications to counteract side-effects (e.g. anti-emetic).

Abbreviations: DMARD, Disease Modifying Anti-Rheumatic Drug; JLS, juvenile localised scleroderma; mLoSSI; modified localised scleroderma skin severity index; MMF, mycophenolate mofetil; MTX, methotrexate

\section{Table 2. Corticosteroid regimens considered during consensus process.}

\begin{tabular}{|c|c|c|c|c|}
\hline & A & B & C & D \\
\hline Route & IV and Oral & Oral & Oral & Oral \\
\hline Regime & $\begin{array}{l}30 \mathrm{mg} / \mathrm{kg} / \mathrm{day} \text { IV } \\
\text { methylprednisolone for } 3 \text { days } \\
\text { followed by: } \\
\text { Oral prednisolone } 1.5 \mathrm{mg} / \mathrm{kg} / \\
\text { day for } 2 \text { weeks (maximum } \\
45 \mathrm{mg} \text { ) then } 1 \mathrm{mg} / \mathrm{kg} \text { for } 2 \text { weeks } \\
\text { (maximum } 30 \mathrm{mg} \text { ) then } 0.5 \mathrm{mg} / \mathrm{kg} \\
\text { for } 2 \text { weeks (maximum } 15 \mathrm{mg} \text { ) } \\
\text { then } 0.25 \mathrm{mg} / \mathrm{kg} / \text { day for } 2 \text { weeks } \\
\text { (maximum } 7.5 \mathrm{mg} \text { ) then stop }\end{array}$ & $\begin{array}{l}\text { Oral prednisolone } \\
1.5 \mathrm{mg} / \mathrm{kg} / \mathrm{day} \text { for } 2 \text { weeks } \\
\text { (maximum } 45 \mathrm{mg} \text { ) then } \\
1 \mathrm{mg} / \mathrm{kg} \text { for } 2 \text { weeks } \\
\text { (maximum } 30 \mathrm{mg} \text { ) then } \\
0.5 \mathrm{mg} / \mathrm{kg} \text { for } 2 \text { weeks } \\
\text { (maximum } 15 \mathrm{mg} \text { ) then } \\
0.25 \mathrm{mg} / \mathrm{kg} / \mathrm{day} \text { for } 2 \\
\text { weeks (maximum } 7.5 \mathrm{mg} \text { ) } \\
\text { then stop }\end{array}$ & $\begin{array}{l}\text { Oral prednisolone } 2 \mathrm{mg} / \mathrm{kg} / \\
\text { day for } 2 \text { weeks (maximum } \\
80 \mathrm{mg} \text { ) then } 1.5 \mathrm{mg} / \mathrm{kg} / \mathrm{day} \\
\text { for } 2 \text { weeks (maximum } \\
45 \mathrm{mg} \text { ) then } 1 \mathrm{mg} / \mathrm{kg} \text { for } 2 \\
\text { weeks (maximum } 30 \mathrm{mg} \text { ) } \\
\text { then } 0.5 \mathrm{mg} / \mathrm{kg} \text { for } 2 \text { weeks } \\
\text { (maximum } 15 \mathrm{mg} \text { ) then } \\
0.25 \mathrm{mg} / \mathrm{kg} / \mathrm{day} \text { for } 2 \text { weeks } \\
\text { (maximum } 7.5 \mathrm{mg} \text { ) then stop }\end{array}$ & $\begin{array}{l}\text { Oral prednisolone } \\
1 \mathrm{mg} / \mathrm{kg} 2 \text { months } \\
\text { then reduce to } \\
0.75 \mathrm{mg} / \mathrm{kg} \text { for } \\
\text { one week then } \\
\text { to } 0.5 \mathrm{mg} / \mathrm{kg} \text { for } \\
\text { one week then to } \\
0.25 \mathrm{mg} / \mathrm{kg} \text { for one } \\
\text { week then stop }\end{array}$ \\
\hline $\begin{array}{l}\text { Total duration of } \\
\text { CS use }\end{array}$ & 3 days IV then 8 weeks oral & 8 weeks & 10 weeks & 11 weeks \\
\hline $\begin{array}{l}\text { Number of experts } \\
\text { that would accept } \\
\text { this regimen in a } \\
\text { clinical trial setting } \\
(\mathrm{n}=12)\end{array}$ & 9 & 12 & 10 & 7 \\
\hline $\begin{array}{l}\text { First choice of CS } \\
\text { regimen chosen by } \\
\text { experts }(n=12)\end{array}$ & 2 & 9 & 1 & 0 \\
\hline
\end{tabular}

Abbreviations: CS, corticosteroid; IV, intravenous; kg, kilogram; mg, milligram 


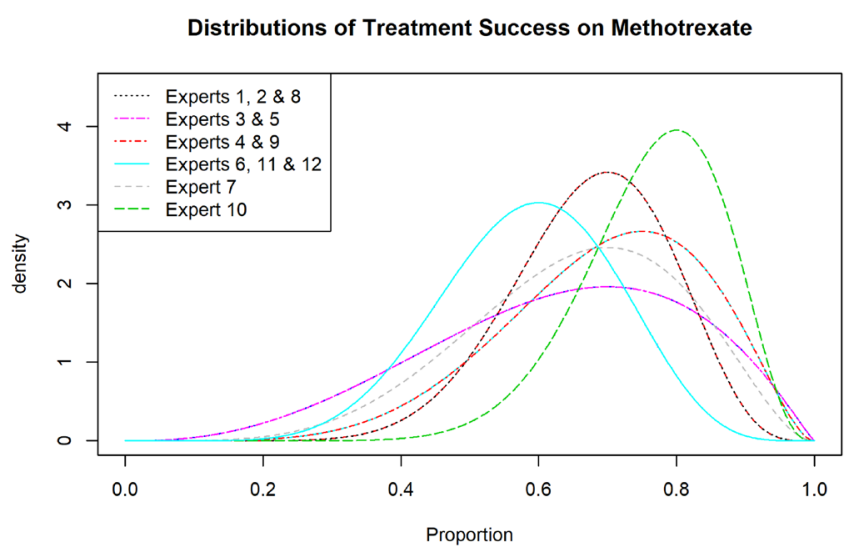

Distributions of Tolerability Success on Methotrexate

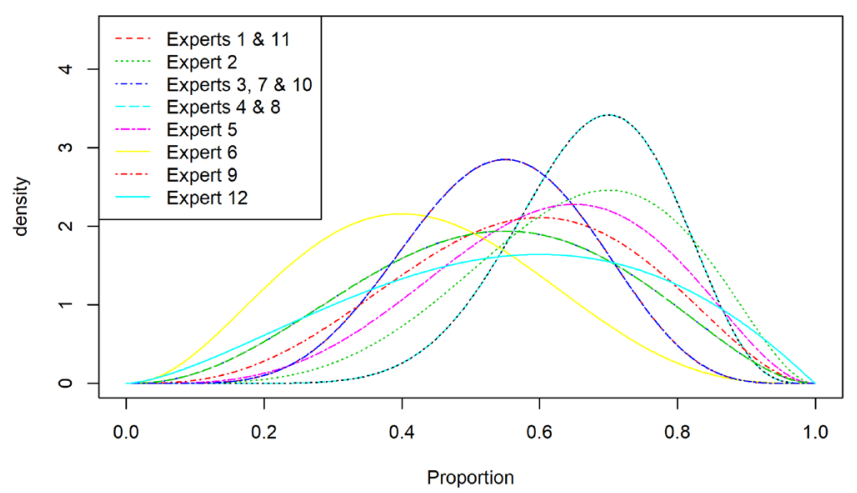

Distributions of Treatment Success on Mycophenolate Mofetil

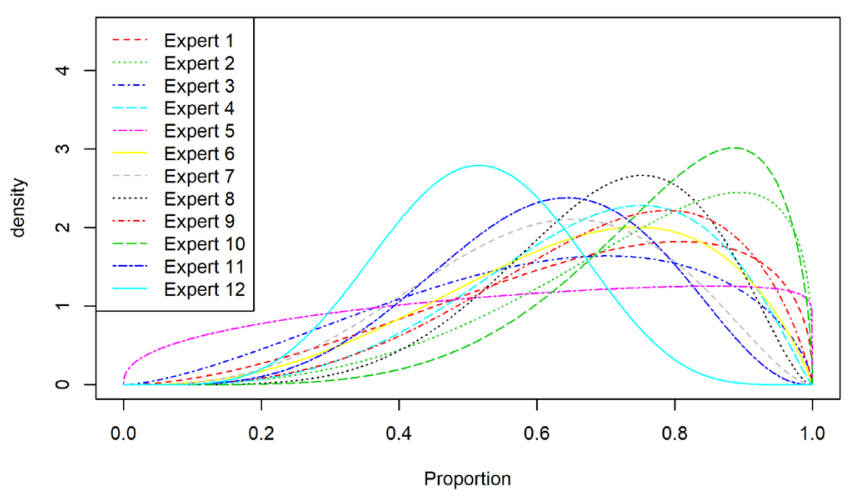

Distributions of Tolerability Success on Mycophenolate Mofetil

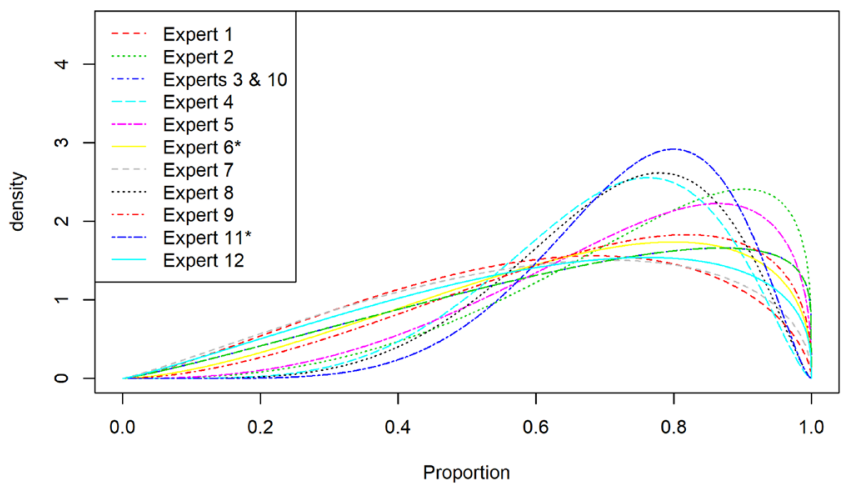

Figure 2. Prior distributions for each expert for MTX (left) and MMF (right) for efficacy (top) and tolerability (bottom).

MMF. All opinions on MMF were derived from the log odds ratio to ensure statistical independence except for two results. In both of these cases, the clinician's opinion on the tolerability of MMF could not be modelled adequately through questions 3 and 4 . This was due to the numerical integration not finding a stable solution due to the experts being either themselves or altogether more uncertain in their opinion on the tolerability of MMF. In these cases, the redundant questions provided the information required. This is shown on Figure 2 with stars where applicable.

From Figure 2, the following conclusions were made: experts were more certain about their opinions on MTX rather than MMF, with multiple experts sharing the same prior distributions; experts seem to believe that MMF is superior in terms of tolerability, however they are uncertain by how much it may outperform MTX.

\section{Consensus prior distributions}

Figure 3 provides the consensus prior distributions, whilst Table 3 presents a summary. Based on the consensus answers of the experts, the most likely value of the efficacy of MTX was $68 \%$ and most likely value of efficacy of MMF was $70 \%$.
The most likely value of tolerability of MTX was $62 \%$ and tolerability of MMF $77 \%$.

We used simulations to explore the properties of different scenarios in order to assess their viability in a future trial. In the 1000 -fold simulations, we fixed $\mathrm{p}_{\mathrm{MTX}}=0.7$ and assumed equal randomisation to the two treatments whilst various values for $\mathrm{p}_{\mathrm{MMF}}$ ranging between $0.55-0.75$ in 0.05 increments were explored. The power for different sample sizes ranging from 40 to 250 using a one-sided type I error of $5 \%$ are provided in Figure 4.

Figure 4 shows that power increases for larger values of $\mathrm{p}_{\mathrm{MMF}}$ as expected. Under the assumption that the efficacy of MMF is similar to MTX (both at $70 \%$ response rate), a sample size of 240 will yield adequate power for this study.

\section{Discussion}

The overall objective of this study was to undertake a prior elicitation process with international experts to determine the efficacy and tolerability of MTX and MMF in JLS. It is evident from the resulting consensus distributions that considerable uncertainty remains concerning the potential merits and 


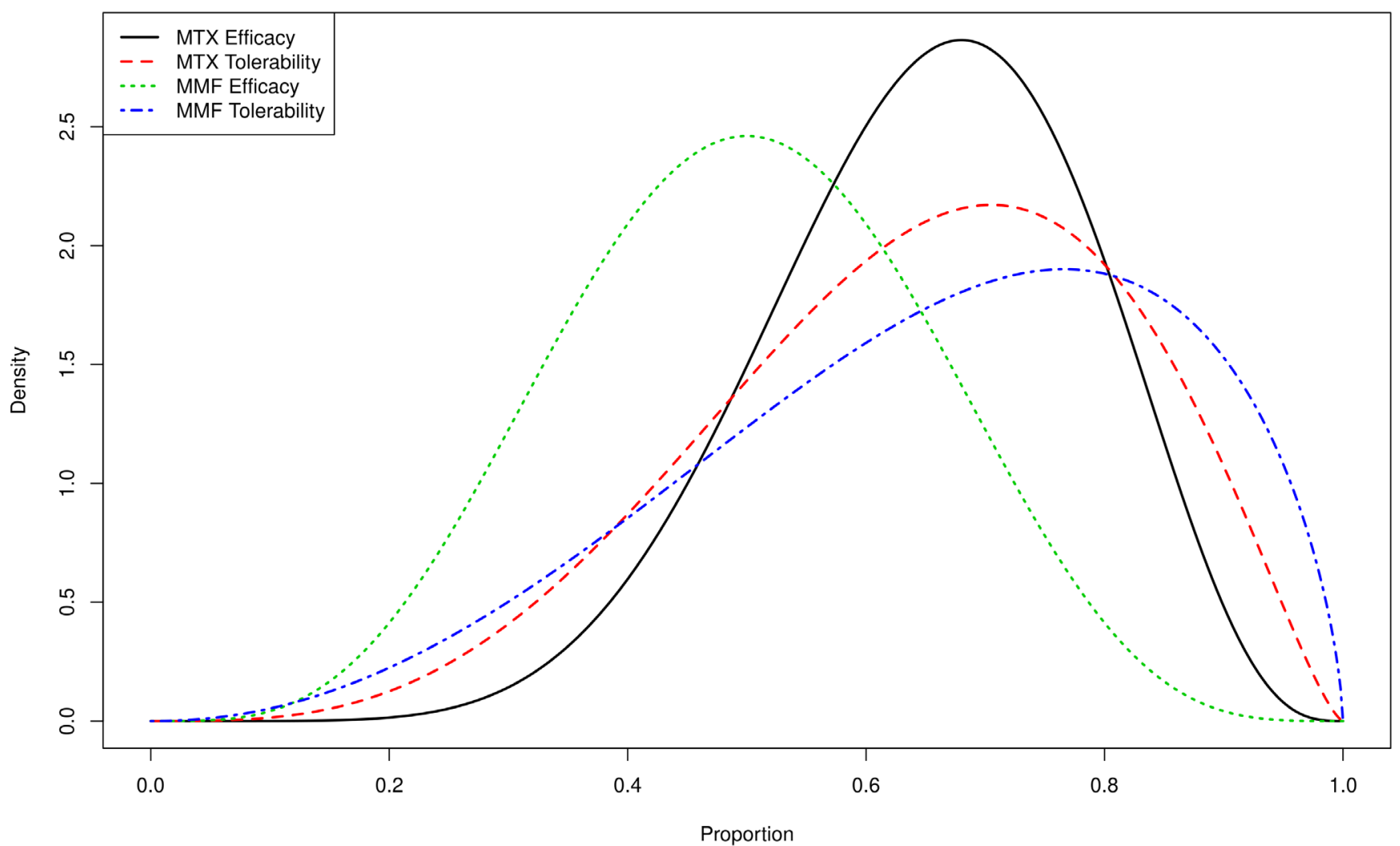

Figure 3. Consensus prior distribution for tolerability and efficacy on MTX and MMF.

Table 3. Summary of consensus prior distributions.

\begin{tabular}{|l|l|l|l|}
\hline Quantity of interest & Most likely value & $\mathbf{5 0 \%} \mathbf{C I}$ & $\mathbf{9 5 \%} \mathbf{C I}$ \\
\hline $\mathrm{P}_{\text {MTX }}$ & 0.680 & $(0.560,0.748)$ & $(0.416,0.854)$ \\
\hline $\mathrm{P}_{\text {MMF }}$ & 0.705 & $(0.527,0.777)$ & $(0.339,0.899)$ \\
\hline $\mathrm{t}_{\text {MTX }}$ & 0.620 & $(0.480,0.711)$ & $(0.316,0.842)$ \\
\hline $\mathrm{t}_{\text {MMF }}$ & 0.766 & $(0.522,0.813)$ & $(0.300,0.936)$ \\
\hline
\end{tabular}

$\mathrm{CI}$, confidence intervals; $\mathrm{p}_{\mathrm{MTX}}$ efficacy of methotrexate; $\mathrm{p}_{\text {MMF }}$ efficacy of mycophenolate mofetil; $\mathrm{t}_{\mathrm{MTX}}$ tolerability of methotrexate; $\mathrm{t}_{\mathrm{MMF}}$ tolerability of mycophenolate mofetil

demerits of MTX and MMF. This Bayesian approach did reduce the sample size from 320 (predictions within a frequentist trial) to 240. However, for such a rare disease, this sample size may still not be feasible. We attempted to use a composite primary outcome encompassing both efficacy and tolerability, which was informed by patients and families. Unfortunately, the arising calculated sample size using efficacy alone as a primary outcome of 240 was high, and would be higher still if a composite score of both efficacy and tolerability was used. A composite primary measure does not therefore appear feasible. Involving patients and their families in the design of a future clinical trial with efficacy as the primary outcome, and adequately capturing tolerability as a key secondary outcome, offers the best opportunity for robustly evaluating further the benefits (or otherwise) of these two medications in the management of JLS.

The uncertainty by experts around response of a medication is not unusual within prior elicitation exercises and was seen in the MYPAN study also ${ }^{33}$. However, other data sources which provide evidence to reduce this uncertainty can then be combined with prior opinion to reduce uncertainty and allow modelling of a lower sample size. This approach was used in the MYPAN study. 


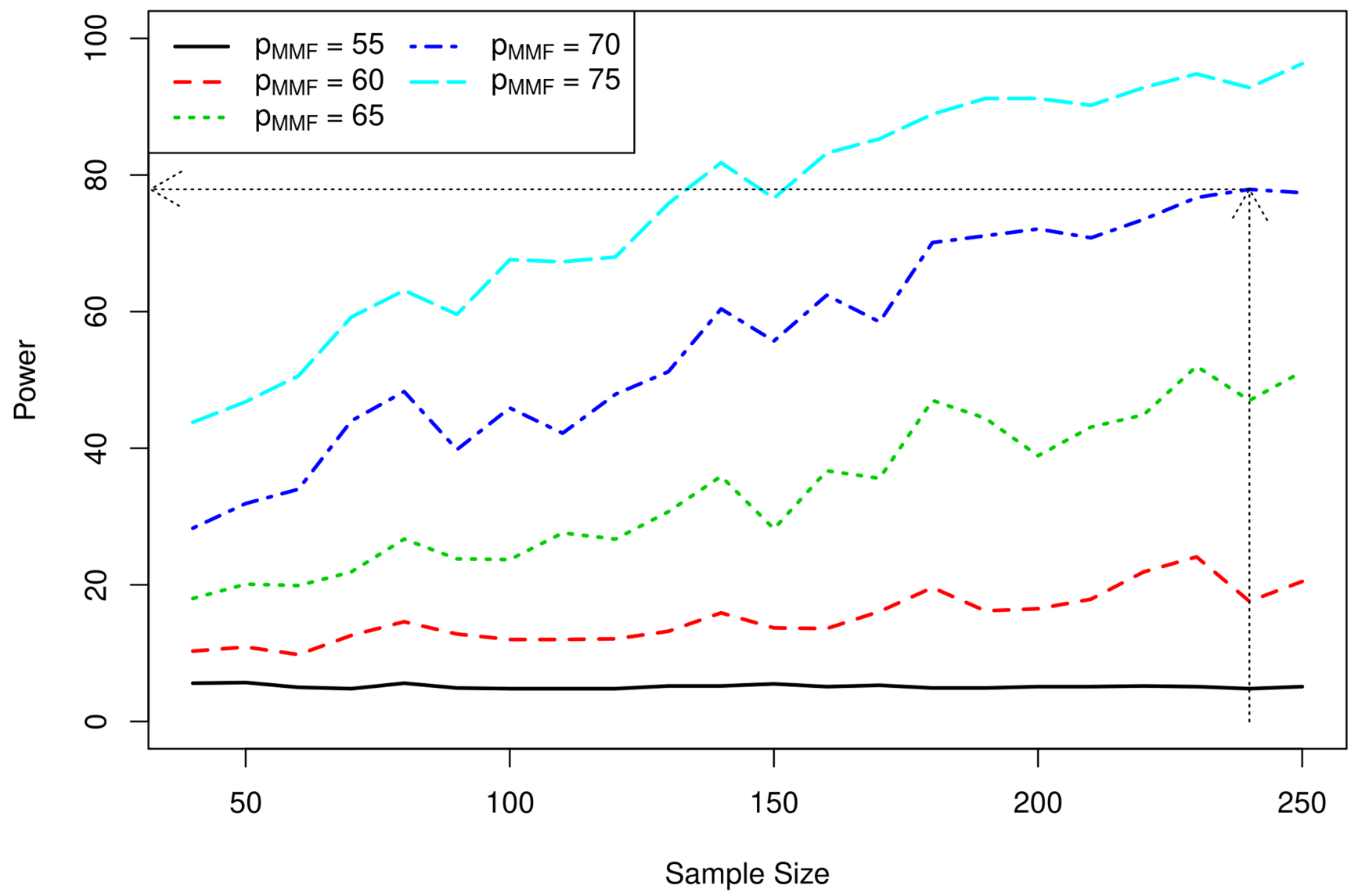

Figure 4. Results of simulations showing potential sample sizes. Legend: pMMF efficacy of mycophenolate mofetil where e.g. $\mathrm{pMMF}=55$ corresponds to efficacy of 55\% (response rate), pMMF $=75$ corresponds to efficacy of $75 \%$. The black dotted line shows that a sample size of 240 would yield power of approximately $80 \%$.

Since the prior elicitation exercise, two further retrospective studies provide further evidence for the efficacy, safety and tolerability of MMF in LS. A case series of MMF in 22 patients with JLS compared to 47 on MTX showed no significant difference in relapse-free survival between the groups although MMF appeared to induce more persistent remission, and MMF was well tolerated ${ }^{40}$. In a study of 77 participants (all 16 years or older), MMF was well tolerated with $35 \%$ achieving disease remission ${ }^{52}$. Both studies concluded that further controlled studies are needed. Statistical analyses of data from these studies may allow reduction of the sample size and a subsequent more feasible trial.

The international experts demonstrated through their prior distributions that they are more certain about the efficacy and tolerability of MTX compared to MMF, most likely relating to their familiarity with MTX as it has been considered 'standard of care' for JLS for some time. There was general consensus that whilst efficacy of MTX and MMF may be similar, MMF is superior in terms of tolerability. If these results could be further supported through clinical trial data, this could provide the first steps to changes in current treatment protocols for JLS.

There was unanimous support for the mLoSSI as the measure of efficacy in a clinical trial. However, within expert group discussions, there was some concern that a mLoSSI score of 0 (definition of efficacy) may be difficult to achieve. There was also consideration given to whether head and face involvement alone should be excluded because of perceived concerns regarding a lower mLoSSI score in this group of children at baseline. However, data presented from the National Registry of Childhood Onset Scleroderma (NRCOS) and Morphea in Adults and Children (MAC) cohort studies ${ }^{51}$ showed that the median mLoSSI was 3 in children (interquartile range (IQR) 0-7) compared to 6 (IQR 0-17) in adults in the combined cohort ( $\mathrm{n}=944 ; 496$ JLS and 443 adult onset LS). The median mLoSSI at baseline in children with nonhead lesions was 7 (IQR 5-12) in $\operatorname{NRCOS~}(n=41)$ and 6.5 (4-12) in MAC $(n=48)$, compared to head only lesions where median mLoSSI was $3(2-4.5)$ in NRCOS $(n=11)$ and $4(3-5)$ in MAC $(n=14)$. Although those with head only LS had a lower 
starting baseline, both head and non-head achieved a mLoSSI score of 0 during follow-up by 6 months across both cohorts. Consensus was achieved to include isolated linear head subtype and to use mLoSSI score of 0 as efficacy end-point at 12 months.

Exclusion criteria were not exhaustively defined but in group discussions it was agreed that this would include participants where the main indication for starting a DMARD was due to extra-cutaneous manifestations such as uveitis or arthritis as the primary efficacy outcome (mLoSSI) only measures skin involvement.

Considerations on CS regimes for a clinical trial setting included the difficulties with a mixed oral and intravenous regime within a clinical trial setting (oral route easier to administer in a multi-centre study) and the importance of limiting the duration of CS to ensure the efficacy of MTX and/or MMF is not masked by the responsive of JLS to CS. This led to consensus regarding regime $\mathrm{B}$ as preferred option which includes oral administration only for the shorter duration of 8 weeks.

Review of the literature preceding the consensus meeting showed a lack of a robust patient-reported outcome for measuring tolerability. The MTX intolerance severity score was reviewed but as this tool has been developed specifically for intolerance related to MTX, it was felt it would not identify some of the more common side-effects of MMF and would add bias to a composite primary endpoint ${ }^{6}$. The Localised Scleroderma Quality of Life Instrument (LoSQI) has been designed in partnership with patients and does include a medication subscale ${ }^{53}$. However, items in the scale were felt to under-represent MMF related side-effects and be weighted towards impact from CS and MTX. This highlights the lack of a generic drug tolerability tool for use in clinical trial settings, when tolerability is being considered as an important end-point.

\section{Conclusions}

We have demonstrated international consensus for a clinical trial of MTX versus MMF in JLS with agreement on primary outcome measure, CS regimes and important inclusion and exclusion criteria. The prior elicitation process showed there was on-going uncertainty over the combined outcome of efficacy and tolerability of MMF versus MTX, highlighting the need for additional clinical data to facilitate future clinical trials.

\section{Data availability}

Figshare. JLS Elicitation Extended data.pdf. DOI: https://doi. org/10.6084/m9.figshare.14994486.v $1^{54}$

This project contains the following underlying data:

JLS Elicitation Extended data.pdf (Extended data from methodology Appendix S1 Participants in prior elicitation meeting; Appendix S2 - Inclusion criteria for a clinical trial of MTX and MMF defined before elicitation exercise; Appendix S3 Detailed methodology of elicitation process.

Data are available under the terms of the Creative Commons Zero "No rights reserved" data waiver (CC0 1.0 Public domain dedication).

Data on $\mathrm{R}$ shiny application used in this study is available on request.

\section{Author contributions}

Conceptualization and funding acquisition: CP, DE, AR, MB, TJ; Pre-meeting evidence synthesis and decision on choice of primary outcome: CP, DE, VL, KT, SL, HJ, TJ, YD; Data curation: CP, DE, KT, TJ, YD; Statistical support TJ, YD, PM, TB; Writing - original draft: YD, TJ, MWB, DE, HJ, VL, SL, AR, KT, CP, Writing - review \& editing: YD, TJ, MWB, TB, DE, HJ, VL, SL, PM, AR, KT, MA, JA, TA, JF, IF, BL, FM, LS, FZ, CP

\section{Acknowledgements}

We are grateful to all who completed the participant survey and to Scleroderma \& Raynaud's UK who kindly funded the study. We are grateful to Jo Jordan and Nadia Corp, systematic review researchers at Keele University for undertaking the literature review of efficacy and tolerability of MTX and MMF in JLS. We acknowledge the UK's Experimental Arthritis Treatment Centre for Children supported by Versus Arthritis, the Alder Hey Charity, Alder Hey Children's NHS Foundation Trust, and the University of Liverpool.
1. Torok KS, Li SC, Jacobe HM, et al.: Immunopathogenesis of Pediatric Localized Scleroderma. Front Immunol. 2019; 10: 908. PubMed Abstract | Publisher Full Text | Free Full Text

2. Zulian F: Systemic sclerosis and localized scleroderma in childhood. Rheum Dis Clin North Am. 2008; 34(1): 239-55; ix. PubMed Abstract

3. Herrick AL, Ennis $\mathrm{H}$, Bhushan $\mathrm{M}$, et al: Incidence of childhood linear scleroderma and systemic sclerosis in the UK and Ireland. Arthritis Care Res
(Hoboken). 2010; 62(2): 213-8. PubMed Abstract | Publisher Full Text

4. Beukelman T, Xie F, Foeldvari I: The prevalence of localised scleroderma in childhood assessed in the administrative claims data from the United States. J Scleroderma Relat Disord. 2018; 4(1): 77-78. Publisher Full Text

5. Zulian F, Martini G, Vallongo C, et al:: Methotrexate treatment in juvenile localized scleroderma: a randomized, double-blind, placebo-controlled 
trial. Arthritis Rheum. 2011; 63(7): 1998-2006. PubMed Abstract | Publisher Full Text

6. Bulatović M, Heijstek MW, Verkaaik M, et al.: High prevalence of methotrexate intolerance in juvenile idiopathic arthritis: development and validation of a methotrexate intolerance severity score. Arthritis Rheum. 2011; 63(7): 2007-13.

PubMed Abstract | Publisher Full Text

7. van der Meer A, Wulffraat NM, Prakken BJ, et al.: Psychological side effects of MTX treatment in juvenile idiopathic arthritis: a pilot study. Clin Exp Rheumatol. 2007; 25(3): 480-5.

PubMed Abstract

8. Torok KS, Arkachaisri T: Methotrexate and corticosteroids in the treatment of localized scleroderma: a standardized prospective longitudinal single-center study. J Rheumatol. 2012; 39(2): 286-94.

PubMed Abstract | Publisher Full Text | Free Full Text

9. Lythgoe $\mathrm{H}$, Almeida B, Bennett J, et al.: Multi-centre national audit of juvenile localised scleroderma: describing current UK practice in disease assessment and management. Pediatr Rheumatol Online J. 2018; 16(1): 80. PubMed Abstract | Publisher Full Text | Free Full Text

10. Martini G, Ramanan AV, Falcini F, et al.: Successful treatment of severe or methotrexate-resistant juvenile localized scleroderma with mycophenolate mofetil. Rheumatology (Oxford). 2009; 48(11): 1410-3. PubMed Abstract | Publisher Full Text

11. Mertens JS, Marsman D, van de Kerkhof PCM, et al.: Use of Mycophenolate Mofetil in Patients with Severe Localized Scleroderma Resistant or Intolerant to Methotrexate. Acta Derm Venereol. 2016; 96(4): 510-3. PubMed Abstract | Publisher Full Text

12. Hawley DP, Pain CE, Baildam EM, et al.: United Kingdom survey of current management of juvenile localized scleroderma. Rheumatology (Oxford). 2014; 53(10): 1849-54.

PubMed Abstract | Publisher Full Text

13. Li SC, Feldman BM, Higgins GC, et al.: Treatment of pediatric localized scleroderma: results of a survey of North American pediatric rheumatologists. J Rheumatol. 2010; 37(1): 175-81. PubMed Abstract | Publisher Full Text

14. Allison AC: Mechanisms of action of mycophenolate mofetil. Lupus. 2005; 14 Suppl 1: s2-8.

PubMed Abstract | Publisher Full Text

15. Roos N, Poulalhon N, Farge D, et al.: In vitro evidence for a direct antifibrotic role of the immunosuppressive drug mycophenolate mofetil. J Pharmacol Exp Ther. 2007; 321(2): 583-9.

PubMed Abstract | Publisher Full Text

16. Hinchcliff M, Huang CC, Wood TA, et al.: Molecular signatures in skin associated with clinical improvement during mycophenolate treatment in systemic sclerosis. J Invest Dermatol. 2013; 133(8): 1979-89.

PubMed Abstract | Publisher Full Text | Free Full Text

17. Herrick AL, Pan X, Peytrignet S, et al.: Treatment outcome in early diffuse cutaneous systemic sclerosis: the European Scleroderma Observational Study (ESOS). Ann Rheum Dis. 2017; 76(7): 1207-1218. PubMed Abstract | Publisher Full Text | Free Full Tex

18. Lee $\mathrm{YH}$, Song GG: Relative efficacy and safety of tacrolimus, mycophenolate mofetil, and cyclophosphamide as induction therapy for lupus nephritis: a Bayesian network meta-analysis of randomized controlled trials. Lupus. 2015; 24(14): 1520-8.

PubMed Abstract | Publisher Full Text

19. Rathi M, Goyal A, Jaryal A, et al:: Comparison of low-dose intravenous cyclophosphamide with oral mycophenolate mofetil in the treatment of lupus nephritis. Kidney Int. 2016; 89(1): 235-42.

PubMed Abstract | Publisher Full Text

20. Tashkin DP, Roth MD, Clements PJ, et al.: Mycophenolate mofetil versus oral cyclophosphamide in scleroderma-related interstitial lung disease (SLS II): a randomised controlled, double-blind, parallel group trial. Lancet Respir Med. 2016; 4(9): 708-19.

PubMed Abstract | Publisher Full Text | Free Full Text

21. Asano $Y$, Fujimoto $M$, Ishikawa $O$, et al.: Diagnostic criteria, severity classification and guidelines of localized scleroderma. J Dermatol. 2018; 45(7): 755-80.

PubMed Abstract | Publisher Full Text

22. Constantin T, Foeldvari I, Pain CE, et al.: Development of minimum standards of care for juvenile localized scleroderma. Eur J Pediatr. 2018; 177(7): 961-77. PubMed Abstract | Publisher Full Text

23. Fett NM: Morphea: evidence-based recommendations for treatment. Indian J Dermatol Venereol Leprol. 2012; 78(2): 135-41. PubMed Abstract | Publisher Full Text

24. Knobler R, Moinzadeh $P$, Hunzelmann $N$, et al:: European dermatology forum S1-guideline on the diagnosis and treatment of sclerosing diseases of the skin, Part 2: Scleromyxedema, scleredema and nephrogenic systemic fibrosis. J Eur Acad Dermatol Venereol. 2017; 31(10): 1581-94. PubMed Abstract | Publisher Full Text

25. Kreuter $A$, Krieg $T$, Worm M, et al.: German guidelines for the diagnosis and therapy of localized scleroderma. J Dtsch Dermatol Ges. 2016; 14(2): 199-216. PubMed Abstract | Publisher Full Text
26. Li SC, Torok KS, Pope E, et al.: Development of consensus treatment plans for juvenile localized scleroderma: a roadmap toward comparative effectiveness studies in juvenile localized scleroderma. Arthritis Care Res (Hoboken). 2012; 64(8): 1175-85.

PubMed Abstract | Publisher Full Text | Free Full Text

27. Zulian F, Culpo R, Sperotto F, et al.: Consensus-based recommendations for the management of juvenile localised scleroderma. Ann Rheum Dis. 2019; 78(8): 1019-24

PubMed Abstract | Publisher Full Text | Free Full Text

28. Le Sache de Peufheiloux L, Benamara-Levy M, Dionne MC, et al.: Treatments and outcomes in juvenile linear scleroderma: a narrative systematic review. Eur J Dermatol. 2018; 28(5): 718-20. PubMed Abstract | Publisher Full Text

29. Shahidi-Dadras M, Abdollahimajd F, Jahangard R, et al.: Magnetic Resonance Imaging Evaluation in Patients with Linear Morphea Treated with Methotrexate and High-Dose Corticosteroid. Dermatol Res Pract. 2018; 2018 8391218

PubMed Abstract | Publisher Full Text | Free Full Text

30. Uziel Y, Feldman BM, Krafchik BR, et al.: Methotrexate and corticosteroid therapy for pediatric localized scleroderma. J Pediatr. 2000; 136(1): 91-5. PubMed Abstract | Publisher Full Text

31. Weibel L, Sampaio MC, Visentin MT, et al.: Evaluation of methotrexate and corticosteroids for the treatment of localized scleroderma (morphoea) in children. Br J Dermatol. 2006; 155(5): 1013-20. PubMed Abstract | Publisher Full Text

32. Hampson LV, Whitehead J, Eleftheriou D, et al:: Bayesian methods for the design and interpretation of clinical trials in very rare diseases. Stat Med. 2014; 33(24): 4186-201. PubMed Abstract | Publisher Full Text | Free Full Text

33. Hampson LV, Whitehead J, Eleftheriou D, et al.: Elicitation of expert prior opinion: application to the MYPAN trial in childhood polyarteritis nodosa. PLoS One. 2015; 10(3): e0120981. PubMed Abstract | Publisher Full Text | Free Full Text

34. Ramanan AV, Hampson LV, Lythgoe $\mathrm{H}$, et al.: Defining consensus opinion to develop randomised controlled trials in rare diseases using Bayesian design: An example of a proposed trial of adalimumab versus pamidronate for children with CNO/CRMO. PLOS One. 2019; 14(6): e0215739. PubMed Abstract | Publisher Full Text | Free Full Text

35. Chang WCJ, Allaire J, Xie Y, et al.: Shiny: Web application framework for $\mathbf{R}$. 2020.

Reference Source

36. R Core Team: R: A language and environment for statistical computing R Foundation for Statistical Computing, Vienna, Austria. 2020. Reference Source

37. O'Hagan T: SHELF: the Sheffield Elicitation Framework. Reference Sourc

38. Arkachaisri T, Vilaiyuk S, Li S, et al.: The localized scleroderma skin severity index and physician global assessment of disease activity: a work in progress toward development of localized scleroderma outcome measures. J Rheumatol. 2009; 36(12): 2819-29. PubMed Abstract | Publisher Full Text | Free Full Text

39. Arkachaisri T, Vilaiyuk S, Torok KS, et al.: Development and initial validation of the localized scleroderma skin damage index and physician global assessment of disease damage: a proof-of-concept study. Rheumatology (Oxford). 2010; 49(2): 373-81. PubMed Abstract | Publisher Full Text | Free Full Text

40. Martini G, Saggioro L, Culpo R, et al.: Mycophenolate mofetil for methotrexate-resistant juvenile localized scleroderma. Rheumatology (Oxford). 2021; 60(3): 1387-1391. PubMed Abstract | Publisher Full Text | Free Full Text

41. Kelsey CE, Torok KS: The Localized Scleroderma Cutaneous Assessment Tool: responsiveness to change in a pediatric clinical population. $\int$ Am Acad Dermatol. 2013; 69(2): 214-20. PubMed Abstract | Publisher Full Text | Free Full Text

42. Agazzi A, Fadanelli G, Vittadello F, et al.: Reliability of LoSCAT score for activity and tissue damage assessment in a large cohort of patients with Juvenile Localized Scleroderma. Pediatr Rheumatol Online J. 2018; 16(1): 37. PubMed Abstract | Publisher Full Text | Free Full Text

43. Skrzypek-Salamon A, Lis-Swiety A, Ranosz-Janicka I, et al.: Localized Scleroderma Cutaneous Assessment Tool (LoSCAT) adapted for use in adult patients: report from an initial validation study. Health Qual Life Outcomes. 2018; 16(1): 185 PubMed Abstract | Publisher Full Text | Free Full Text

44. Teske NM, Jacobe HT: Using the Localized Scleroderma Cutaneous Assessment Tool (LoSCAT) to classify morphoea by severity and identify clinically significant change. Br J Dermatol. 2020; 182(2): 398-404. PubMed Abstract | Publisher Full Text

45. Ardalan K, Zigler CK, Torok KS: Predictors of Longitudinal Quality of Life in Juvenile Localized Scleroderma. Arthritis Care Res (Hoboken). 2017; 69(7): $1082-7$.

PubMed Abstract | Publisher Full Text | Free Full Text 
46. Kurzinski KL, Zigler CK, Torok KS: Prediction of disease relapse in a cohort of paediatric patients with localized scleroderma. BrJ Dermatol. 2019; 180(5): 1183-9.

PubMed Abstract | Publisher Full Text | Free Full Text

47. Condie D, Grabell D, Jacobe H: Comparison of outcomes in adults with pediatric-onset morphea and those with adult-onset morphea: a crosssectional study from the morphea in adults and children cohort. Arthritis Rheumatol. 2014; 66(12): 3496-504. PubMed Abstract | Publisher Full Text | Free Full Text

48. Johnson W, Jacobe $\mathrm{H}$ : Morphea in adults and children cohort II: patients with morphea experience delay in diagnosis and large variation in treatment. J Am Acad Dermatol. 2012; 67(5): 881-9. PubMed Abstract | Publisher Full Text

49. Kunzler E, Florez-Pollack S, Teske N, et al.: Linear morphea: Clinical characteristics, disease course, and treatment of the Morphea in Adults and Children cohort. J Am Acad Dermatol. 2019; 80(6): 1664-70.e1. PubMed Abstract | Publisher Full Text

50. Li SC, Torok KS, Rabinovich CE, et al.: Initial Results from a Pilot Comparative
Effectiveness Study of 3 Methotrexate-based Consensus Treatment Plans for Juvenile Localized Scleroderma. J Rheumatol. 2020; 47(8): 1242-52. PubMed Abstract | Publisher Full Text

51. Prasad SSK, Haley R, Torok K, et al.: Further Characterizing Morphea Subset Using a Multi-center, Prospective, Cross-sectional Analysis of Morphea in Adults and Children. Arthritis Rheum. 2019; 71(suppl 20). Reference Source

52. Arthur M, Fett NM, Latour E, et al.: Evaluation of the Effectiveness and Tolerability of Mycophenolate Mofetil and Mycophenolic Acid for the Treatment of Morphea. JAMA Dermatol. 2020; 156(5): 521-8. PubMed Abstract | Publisher Full Text | Free Full Text

53. Zigler CK, Ardalan K, Lane S, et al.: A novel patient-reported outcome for paediatric localized scleroderma: a qualitative assessment of content validity. BrJ Dermatol. 2020; 182(3): 625-35. PubMed Abstract | Publisher Full Text | Free Full Text

54. Pain C, desai y, jaki t, et al.: JLS Elicitation Extended data.pdf. figshare. Journal contribution. 2021.

http://www.doi.org/10.6084/m9.figshare.14994486.v1 


\section{Open Peer Review}

\section{Current Peer Review Status:}

\section{Version 1}

Reviewer Report 07 March 2022

https://doi.org/10.21956/amrcopenres.14083.r26901

(C) 2022 Hong S. This is an open access peer review report distributed under the terms of the Creative Commons Attribution License, which permits unrestricted use, distribution, and reproduction in any medium, provided the original work is properly cited.

\section{Sandy Hong}

Department of Pediatrics, Division of Rheumatology, University of Iowa Stead Family Children's Hospital, Iowa City, IA, USA

Summary: This article was a report of pre-trial expert consensus and modeling with a Bayesian approach to decrease the " $\mathrm{N}$ " or power (number of subjects) needed to perform a clinical trial to statistically evaluate the efficacy of MMF versus MTX for the treatment of juvenile Localised Scleroderma.

It basically showed that even with a large group consensus that MMF works- the $\mathrm{N}$ for a trial is still large if using only efficacy as an endpoint. The authors suggest tolerability must be included as an endpoint.

The article was very well written. It can be improved slightly in the conclusion section.

My questions to help inform the conclusion or if the conclusion can allude to:

1. Where are they going to get more clinical data to facilitate a future clinical trial? Will they use an existing registry? What about the development of a pilot Consensus Treatment Trials across their multiple international institutions with physician and patient entered data about efficacy and tolerability?

Is the work clearly and accurately presented and does it cite the current literature? Yes

Is the study design appropriate and is the work technically sound? Yes

Are sufficient details of methods and analysis provided to allow replication by others? Yes

If applicable, is the statistical analysis and its interpretation appropriate? 
Yes

Are all the source data underlying the results available to ensure full reproducibility? Yes

Are the conclusions drawn adequately supported by the results?

Yes

Competing Interests: No competing interests were disclosed.

Reviewer Expertise: linear scleroderma

I confirm that I have read this submission and believe that I have an appropriate level of expertise to confirm that it is of an acceptable scientific standard.

Reviewer Report 24 September 2021

https://doi.org/10.21956/amrcopenres.14083.r26789

(C) 2021 Jelusic $\mathbf{M}$ et al. This is an open access peer review report distributed under the terms of the Creative Commons Attribution License, which permits unrestricted use, distribution, and reproduction in any medium, provided the original work is properly cited.

\section{Marija Jelusic}

Department of Pediatrics, School of Medicine, University of Zagreb, Zagreb, Croatia

Mario Sestan

Department of Paediatrics, University of Zagreb School of Medicine, Zagreb, Zagreb, Croatia

The manuscript of Desai et al. represents the results of an international consensus meeting on the relative efficacy and tolerability of MTX compared to MMF in the treatment of juvenile localised scleroderma to develop the design of a potential future trial comparing MMF to MTX.

The subject of manuscript is relevant since the treatment of juvenile localised scleroderma is challenging and there is a lack of randomised trials.

The abstract of the manuscript is clear and comprehensible, it contains general aims of the research and these are to undertake a prior elicitation process with international experts to determine the efficacy and tolerability of MTX and MMF in the treatment of juvenile localised scleroderma and to achieve consensus agreement on critical aspects of a future trial. The methods used in the research are also briefly presented, and at the end of the abstract the expected contribution of the research is described. All the data presented in the abstract are described in detail in other parts oof the manuscript. The abstract is written in such a way that it is clear to the general medical public what the manuscript is about.

The introduction is coherently written and the literature references are relevant for the proposed subject of research. In the introduction the authors presented all relevant research and data 
needed to follow-up and understand other parts of the manuscript. The authors successfully summarized all pertinent knowledge to date related to the therapy of juvenile localised scleroderma with MTX and MMF.

The general aims of the manuscript are clear and concise. The research is designed so that the general goals are achievable and accessible. The goals were achieved due to well-planned international consensus meeting.

The section "Methods" understandably describes what has been done. The methods used in the manuscript are presented plainly. The authors used proven approach previously well described in the literature and used in paediatric rheumatology clinical trials such as the MYPAN trial.

The data were interpreted using appropriate statistical methods, which is briefly explained. Applying the above methods listed aims were achieved. The results are distinctly presented accompanied with three figures and three tables. Based on the presented results, it can be concluded that manuscript provides scientific contribution to problems stemming from the authors' work. These results may represent the starting point for future Bayesian approach clinical trial.

The discussion is concise and all important results are analysed in detail.

We have a few questions for authors where the answers to them do not necessarily have to be included in the manuscript itself.

The introductory part of the manuscript provides data on incidence of juvenile localised scleroderma in the UK and a prevalence in the USA, followed by an illustrative example how with the number of new cases in the UK it would take at least 15 years to complete the study to allow direct comparison of the efficacy and tolerability of the two treatments. Since prevalence and incidence data differ in different parts of the world, can the authors provide data for some other parts of the world that would be of interest to readers?

In the manuscript the authors presented their dilemma whether to exclude a group of children with head only localised scleroderma. Since there are several subtypes of the disease and it can affect different tissue depths, do the authors believe that the effectiveness of drugs may be different depending on the subtype, or depending on the extent of the disease and the depth of tissue involvement?

Furthermore, do the authors consider that the duration of the disease before starting therapy may affect the effectiveness of drugs or the difference in effectiveness in the context of the fact that MMF may have an effect on both the inflammatory and fibrotic aspects of this disease? Would drug efficacy considerations change for patients with longer disease duration or with advanced disease?

The authors stated that they took into account representation from UK and non-UK sites when forming the expert group, and in the Extended data that at least two representatives were dermatologists. From the Figure 2 it was concluded that the experts were more certain about their opinions on MTX rather than MMF. Were there significant differences of opinion as to whether the experts came from the UK or outside the UK or whether they were dermatologists or 
rheumatologists?

Since one of the ultimate goals of future research is to suggest which drug should be the first choice of therapy, MTX or MMF, do the authors consider whether the variable of prices and availability of both drugs to the patients in different countries should be considered - whether the MMF justifies better or the same effect and fewer side effects compared to MTX to be recommended as first line therapy?

Finally, we would like to thank the authors for their interesting manuscript and the opportunity to present our comments and wish them much success in future research on juvenile scleroderma, where therapeutic options are still quite limited and treatment alone is a major challenge in clinical practice.

Is the work clearly and accurately presented and does it cite the current literature? Yes

Is the study design appropriate and is the work technically sound?

Yes

Are sufficient details of methods and analysis provided to allow replication by others?

Yes

If applicable, is the statistical analysis and its interpretation appropriate? Yes

Are all the source data underlying the results available to ensure full reproducibility? Yes

Are the conclusions drawn adequately supported by the results?

Yes

Competing Interests: No competing interests were disclosed.

Reviewer Expertise: Paediatric rheumatology, especially vasculitis.

We confirm that we have read this submission and believe that we have an appropriate level of expertise to confirm that it is of an acceptable scientific standard. 